\title{
Common Epitope in Human Immunodeficiency Virus (HIV) I-GP41 and HLA Class II Elicits Immunosuppressive Autoantibodies Capable of Contributing to Immune Dysfunction in HIV I-infected Individuals
}

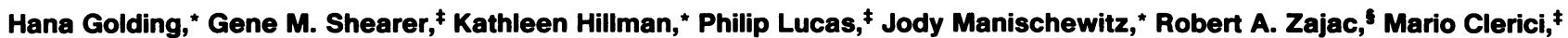 \\ Ronald E. Gress, ${ }^{\ddagger}$ R. Neal Boswell, ${ }^{5}$ and Basil Golding" \\ *Division of Virology, Food and Drug Administration (FDA), "Laboratory of Cell Biology, Division of Blood and Blood Products, FDA, \\ ${ }^{\ddagger}$ Experimental Immunology Branch, National Cancer Institute, National Institutes of Health, Bethesda, Maryland 20892; and ${ }^{\S}$ Human \\ Immunodeficiency Virus Unit/SGHMMM, Wilford Hall, Lackland Air Force Base, Texas 28236
}

\begin{abstract}
We previously reported the identification of highly conserved homologous regions located in the carboxy terminus of the HIV I gp41-envelope (aa 837-844), and the amino-terminal of the beta chain of all human HLA class II antigens (aa 19-25). Murine monoclonal antibodies, raised against synthetic peptides from these homologous regions, bound not only to the isolated peptides, but also to the native gp160 and class II molecules. In this study one-third of sera from HIV I-infected individuals, at different disease stages, were found to react with both the gp41 and class II-derived peptides. These sera also reacted with "native" HLA class II molecules. The potential affects of such autoantibodies on normal immune functions were examined. It was found that in the presence of class IIcross-reactive (but not control) sera, the proliferative responses of normal $\mathrm{CD4}^{+} \mathrm{T}$ cells to tetanus toxoid and allogeneic stimuli were markedly decreased. In addition, these sera could eliminate class II-bearing cells by antibody dependent cellular cytotoxicity. Similar affects were seen with affinitypurified IgG antibodies from patients' sera.

Thus, the "molecular mimicry" between HIV I and HLA class II antigens, may lead to the generation of autoantibodies in HIV I-infected individuals that may contribute to the early functional impairment of $\mathrm{CD4}^{+} \mathrm{T}$ cell observed in many HIV I-infected individuals.
\end{abstract}

\section{Introduction}

Molecular mimicry between a component of an infectious agent and "self" molecules has been postulated to lead to the breakdown of immunological self-tolerance and the generation of harmful autoreactive antibodies and/or effector $\mathbf{T}$ cells (1-3).

We have previously reported the results of a computer search which identified homologous sequences located in the $\mathrm{COOH}$-terminus of HIV I-gp41, and in the $\mathrm{NH}_{2}$-terminal do-

Address reprint requests to Dr. H. Golding, Division of Virology, CBER, FDA, Building 29A, Room 2D20 (H7B-500), 8800 Rockville Pike, Bethesda, MD 20892.

Received for publication 11 October 1988 and in revised form 16 December 1988.

The Journal of Clinical Investigation, Inc.

Volume 83, April 1989, 1430-1435 main of human class II beta chains (Fig. 1 and reference 4). The homologous sequence is highly conserved among different HIV I isolates, and in different class II subregions (DP, DQ, and DR) and haplotypes. Murine monoclonal antibodies (MAb) specific for the gp41-derived sequence were found to cross-react with the class II-derived peptide and recognized native class II molecules expressed by $B$ cell lines and by mouse L cells transfected with the structural genes of DP, DQ, or DR (4).

Screening of sera from AIDS patients revealed a significant number that contained antibodies specific for the gp41-derived sequence (aa 837-844). More importantly, such sera cross-reacted not only with the homologous peptide derived from HLA class II, but also recognized "native" class II molecules. Thus, it was conceivable that the molecular mimicry between HIV I envelope and HLA class II leads to the generation of autoreactive antibodies in HIV I-infected individuals. Binding of such antibodies to class II bearing cells such as macrophages and activated $T$ cells could interfere with normal antigen presentation and/or lead to destruction of activated $\mathrm{CD}^{+} \mathrm{T}$ cells, not yet infected with the virus. Such mechanisms could account for the early $T$-helper cell dysfunctions identified in many HIV I-infected individuals before the marked reduction in their $\mathrm{CD}^{+} \mathrm{T}$ cell numbers that takes place in more advanced stages of the disease.

In this study sera from HIV-I-infected individuals at various disease stages were tested for the presence of cross-reactive anti-class II antibodies and for their ability to inhibit $\mathrm{CD}^{+} \mathrm{T}$ cells in vitro. The results suggest that the selective immune dysfunction of $\mathrm{CD}^{+} \mathrm{T}$ cells, can be brought about, at least in part, by autoantibodies that cross-react on an epitope common to gp41 and HLA class II molecules.

These findings also have important implications for the future design of subunit vaccines containing the gp160 envelope.

\section{Methods}

Enzyme linked immunosorbent assay (ELISA). 96 well plates (Immunolon I; Dynatech Laboratories, Inc., Alexandria, VA) were coated with peptides at $10 \mu \mathrm{g} / \mathrm{ml}$ in bicarbonate buffer at pH 9.6. BSA, 1 $\mathrm{mg} / \mathrm{ml}$ in PBS was added to block unbound sites. Patients' sera were incubated at serial dilutions $(1: 100-1: 400)$ for $2 \mathrm{~h}$ at room temperature. This was followed by incubation with goat anti-human IgG alkaline phosphatase-linked antibody (Sigma Chemical Co., St. Louis, MO) for $2 \mathrm{~h}$ at room temperature. Color was developed by addition of 
Table I. Murine MAb against gp41-derived Peptide (aa 837-844) Can Block the Proliferative Response of Human $C D 4^{+}$ T Cell Clone

\begin{tabular}{ccccc}
\hline & & & \multicolumn{2}{c}{$\left[{ }^{3} \mathrm{H}\right]$ Thymidine uptake } \\
\cline { 4 - 5 } Responder & Stimulator & MAb-inhibitor & $\mathrm{cpm}^{*}$ & $\%$ control \\
\hline T cell clone & B cell line & - & $10,494+227$ & $100 \%$ \\
(G916-3-53) & (Z2B) & & & \\
& & Anti-CD4 & $3,657+594$ & $34 \%$ \\
& & Anti-CD8 & $9,422+94$ & $90 \%$ \\
& & Anti-DP & $1,875+55$ & $18 \%$ \\
& & Anti-class I & $12,518+94$ & $119 \%$ \\
& & Anti-gp41 & & \\
& & -peptide (\#3) & $3,213+350$ & $31 \%$ \\
& & Anti-gp41 & & \\
& & -peptide (\#4) & $2,763+638$ & $26 \%$ \\
& & Anti-DNP (C1) & $11,005+490$ & $104 \%$
\end{tabular}

Responder $T$ cells and stimulator B cells (DP2 ${ }^{+}, 10,000$ rads irradiated), were cultured at $1: 1$ ratio $\left(2.5 \times 10^{4} /\right.$ well $)$ for $3 \mathrm{~d}$ in the presence or absence of the murine MAb. $\left[{ }^{3} \mathrm{H}\right]$ Thymidine was added for the last $16 \mathrm{~h}$.

* All the $\mathrm{cpm}$ values represent net $\mathrm{cpm}=$ total $\mathrm{cpm}-[\mathrm{cpm}$ of responders only $+\mathrm{cpm}$ of stimulators only].

the substrate, $p$-nitrophenyl phosphate for $1-3 \mathrm{~h}$ at room temperature. The optical densities were read at $405 \mathrm{nM}$ using a multiscan MC (Titertek, Helsinki, Finland).

In vitro proliferative responses. The DP2-allospecific $\mathrm{T}$ cell clone (G916-3-53, $2.5 \times 10^{4} /$ well) was stimulated for $3 \mathrm{~d}$ with the EBV transformed B cell line (Z2B, $2.5 \times 10^{4} /$ well). Normal PBL $\left(5 \times 10^{5} /\right.$ well) were stimulated for $7 \mathrm{~d}$ with tetanus toxoid ( $40 \mathrm{fu} / \mathrm{ml}, 25 \mu \mathrm{g} / \mathrm{ml}$ ) or with the mitogen PHA $(2 \mu \mathrm{g} / \mathrm{ml})$. $\left[{ }^{3} \mathrm{H}\right]$ Thymidine $(1 \mu \mathrm{Ci} /$ well $)$ was added to either culture for the last $16 \mathrm{~h}$ of culture. Patients' (or control) sera were added to the responder cells (1:20 final dilution), $30 \mathrm{~min}$ before the addition of stimulators or antigens, and were present throughout the culture period. Murine MAb used; anti-CD4, OKT4A and anti-CD8, OKT8 were from Ortho Pharmaceutical Corp., Raritan, NJ. Anti-DP B721 and anti-class I W632 were a gift from W. Biddison, Neurobiology Branch, NIMH, National Institutes of Health. Anti-DR and anti-DQ were obtained from Becton Dickinson Co., Mountain View. These MAb were added to cultures at 1:200 final dilutions.

Antibody dependent cellular cytotoxicity (ADCC). ${ }^{1}$ ADCC of class II-positive and class II-negative cell lines was conducted as previously described (5). Briefly, targets were labeled with ${ }^{51} \mathrm{Cr}$ for $1 \mathrm{~h} .10^{4}$ labeled targets were incubated in round bottomed 96 well plates with $50 \mu$ lest sera at $1: 25$ dilution for $30 \mathrm{~min}$ at $37^{\circ} \mathrm{C}$ followed by addition of 2.5 $\times 10^{5}$ normal PBL (Ficoll-purified) as effector cells. ${ }^{51} \mathrm{Cr}$ release was measured after $16 \mathrm{~h}$ incubation at $37 \mathrm{C}$ in $5 \% \mathrm{CO}_{2}$.

Electrophoresis in polyacrylamide gel. Column eluates were concentrated using an Amicon Centricon-10 (Amicon Corp., Danvers, MA), and were mixed with amplified sample buffer. Samples were run on a $7.5 \%$ nonreducing polyacrylamide gel (mini-protean II; Bio-Rad Laboratories, Richmond, CA) at constant voltage $(200 \mathrm{~V})$ for $42 \mathrm{~min}$. The gel was stained with brilliant Coomassie blue 250 .

\section{Results}

Murine monoclonal antibodies against the homologous peptide from gp4l recognize native human class II HLA antigens and

1. Abbreviations used in this paper: ADCC, antibody dependent cellular cytotoxicity. can block in vitro proliferative response of a $C D 4^{+}$human $T$ cell clone. To assess the biological relevance of the sequence homology found in gp41 and all human class II beta chains (Fig. 1), we first tested the ability of murine MAb specific for the gp41-derived sequence (that were previously shown to bind also to native class II molecules, reference 4 ), to block the proliferative response of a DP-allospecific $\mathrm{CD}^{+} \mathrm{T}$ cell clone. As can be seen in Table I, the proliferative response of this clone can be blocked by anti-DP MAb as well as by anti-CD4 MAb (OKT4A), but not by anti-class I or by anti-CD8 MAb. In addition, the two anti-gp41 peptide murine $\mathrm{MAb}$ ( 3 and 4), but not a control isotype matched ani-DNP MAb, inhibited this proliferative response by $75 \%$. The same MAb had no effect on the function of control $\mathrm{CD}^{+} \mathrm{T}$ cell clones.

The ability of murine anti-gp41-peptide MAb to bind to native class II molecules and to block stimulation of the $\mathrm{CD}^{+}$ $\mathrm{T}$ cell line, suggested that the binding to class II molecules occurs close to a site on the class II molecules that is recognized by either the antigen-specific $T$ cell receptor, or by the accessory molecule CD4. CD4 binding has been shown to increase the avidity of the cellular interaction between $\mathrm{CD}^{+} \mathrm{T}$ cells and their targets or antigen presenting cells (6).

Association of HIV I infection with production of antigp41/class II cross-reactive antibodies. Previously we have shown that natural infection with HIV I gave rise in AIDS patients to antibodies that reacted with the common epitope shared by gp 41 and class II antigens and that this reactivity correlated with their ability to bind to intact class II molecules as determined by ELISA ( $r=0.846$, reference 4$)$. In this study we extended our screening of HIV I-seropositive individuals in order to determine at what stage of the infection these antibodies appear, and whether they have deleterious effects on the function of $\mathrm{CD}^{+} \mathrm{T}$ cells.

Patients at different disease stages as well as appropriate control groups were studied (Table II). We included among our controls, patients with other disorders shown to have reduced $\mathrm{CD}^{+}{ }^{+}$T-helper functions (e.g., Hodgkin's lymphoma and cyclosporin-treated kidney transplant recipients). In addition, high risk HIV I-seronegative homosexuals and normal volunteers were tested.

None of the control sera reacted with the class II-derived peptide in ELISA. This was to be expected, since it is a highly conserved sequence and most likely to be under self-tolerance control. It is interesting that among the HIV I-infected individuals, irrespective of their disease state, $30-35 \%$ reacted in ELISA asay with the class II-derived-peptide (but not with control peptides derived from class II, CD4, or tetanus toxoid). This proportion may be an underestimation of the number of patients producing such antibodies, since most of the antibod-

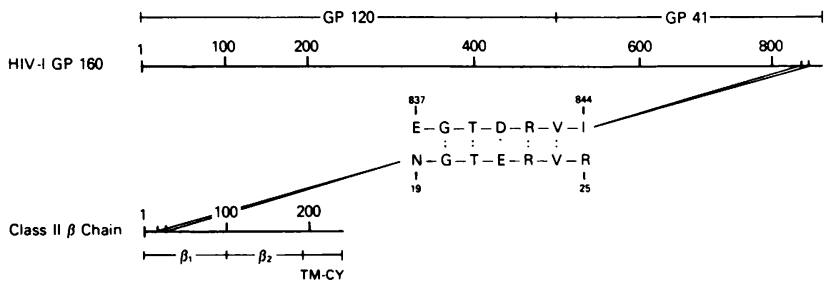

Figure 1. The homologous sequences found in HIV I gp41 and human HLA class II beta chains. : represent identical amino acids, . represent a conservative amino acid difference. 
Table II. Association of HIV I Infection with Production of Anti-class II/gp41 Cross-reactive Antibodies

\begin{tabular}{lccc}
\hline & \multicolumn{3}{c}{ Anti-class II-peptide antibodies } \\
\cline { 2 - 4 } \multicolumn{1}{c}{ Diagnosis } & No. positive & No. tested & $\%$ \\
\hline HIV I seropositive: & & & \\
Stages 1-3 & 18 & 51 & $35 \%$ \\
Stages 4-6 (USA) & 15 & 43 & $35 \%$ \\
$\quad$ (Zaire) & 5 & 18 & $28 \%$ \\
HIV I seronegative: & & & \\
High risk & 0 & 21 & $0 \%$ \\
Low risk & 0 & 35 & $0 \%$ \\
Hodgkin's lymphoma & 0 & 6 & $0 \%$ \\
Transplant recipients & 0 & 4 & $0 \%$ \\
\end{tabular}

ies are probably bound to class II-bearing cells in vivo rather than freely circulating in the serum.

The finding of this anti-class II reactivity in early stages of HIV I infection supports the notion that they may play a role in the pathogenesis of AIDS. The different serum groups were next tested for their functional activity.

Sera from HIV I-infected individuals, which contain anticlass II cross-reactive antibodies, block immune responses of normal $T$ cells, and can eliminate class II-bearing cells by $A D C C$. In order to test the ability of sera to affect $\mathrm{CD}^{+} \mathrm{T}$ cell responses, they were added to cultures of $(a)$ human class II allospecific (anti-DP2) CD4 ${ }^{+} \mathrm{T}$ cell clone (G916-3-53) stimulated with DP2-positive stimulators (same as in Table I), or (b) normal PBL stimulated with the recall antigen tetanus toxoid. As can be seen in Fig. 2, both proliferative responses were mediated by $\mathrm{CD}^{+} \mathrm{T}$ cells, and were blocked by the anti-CD4 MAb OKT4A. In addition they were blocked by monomorphic anti-class II MAb, but not by anti-class I MAb (D, H). The addition of HIV I-negative sera (A, E), or HIV I-positive sera, which do not contain anti-class II peptide reactivity (B, F), did not interfere with either response, except for one HIV I-positive serum $(\mathrm{F})$. In contrast, $\sim 75 \%$ of the sera containing anti-class II antibodies caused marked inhibition (30-100\%) of both the antitetanus toxoid response and the DP-specific $T$ cell clone response $(\mathrm{C}, \mathrm{G})$.

The same sera were also tested for their ability to mediate killing of class II-bearing lymphoblastoid lines in the presence of normal PBL as a source of Fc bearing killer cells (Fig. 3). It was found that about half of the HIV I-positive sera which react with class II-peptide could mediate killing of class IIbearing cells, which was at least 3 SD above that of class II negative control cells. In contrast, none of the seronegative control sera, or the seropositive sera which did not react with class II peptide mediated killing in the ADCC assay (Fig. 3). The murine MAb against the class II-derived peptide did not mediate ADCC because they all belonged to the IgM class which, unlike IgG, does not bind to Fc receptors of human monocyte effector cells. It is important to emphasize that the human sera demonstrating the immunosuppressive activity (or able to mediate ADCC), were equally represented in patients at early or late stages of HIV I infection.

Purification of anti-class II cross-reactive antibodies from HIV I-positive patients' sera. To determine whether the inhibitory effects of these sera could indeed be attributed to their reactivity with the homologous class II/gp41 sequence, they were adsorbed overnight with the class II-derived peptide conjugated to Sepharose beads or with control peptide-Sepharose beads (derived from CD4 aa 314-331). Indeed it was possible to remove most of the inhibitory activity of the sera by adsorption with the relevant peptide but not with the irrelevant control peptide (Fig. 4). In parallel experiments it was found that the gp41-derived peptide was as efficient in removing the inhibitory antibodies as the class II derived homologous peptide (not shown). With some of the antisera, the overnight adsorption (at 1:1 ratio) was not sufficient to remove all the inhibitory activity (e.g., Fig. 4, open circles). In most cases a second adsorption could remove the residual inhibitory activity, but a few antisera remained moderately suppressive (25-35\% inhibition) especially in the $\mathrm{T}$ cell clone assay, suggesting the presence of other inhibitory factors (e.g., antibodies against an activated $\mathrm{T}$ cell determinant as was previously described, reference 7).

A total of 36 sera were tested in all three assays, namely ADCC and the two different proliferative responses. A 95\% concordance was found among these assays. Two sera suppressed the proliferative responses but did not mediate ADCC, which may reflect antibodies of subclasses that do not function in this assay. More importantly, both reactivities (suppression of human $\mathrm{CD}^{+}$cells in cultures, and killing of class II-ex-

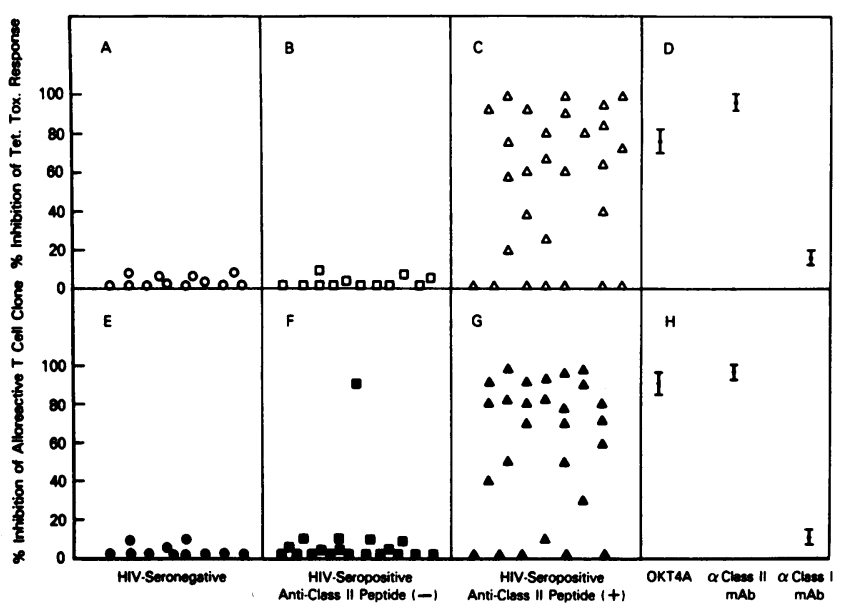

Figure 2. Sera from HIV I positive individuals which react with class Il-derived peptide inhibit normal immune responses in vitro. HIV I negative and positive antisera which were previously screened for their reactivity with the homologous GP41/HLA class II peptides, were added (at 1:20 dilution) to in vitro cultures of $(A, B, C)$ normal PBL $\left(5 \times 10^{5} /\right.$ well) stimulated for $7 \mathrm{~d}$ with tetanus toxoid $(25$ $\mu \mathrm{g} / \mathrm{ml})$, or $(E, F, G)$ DP-allospecific $\mathrm{T}$ cell clone (G916-3-53, 2.5 $\times 10^{4} /$ well) stimulated for $3 \mathrm{~d}$ with the EBV transformed B cell line Z2B $\left(2.5 \times 10^{4} /\right.$ well $) .\left[{ }^{3} \mathrm{H}\right]$ Thymidine $(1 \mu \mathrm{Ci} /$ well $)$ was added for the last $16 \mathrm{~h}$ of culture. The anti-CD4 MAb OKT4A (Ortho) was added at 1:200 final dilution. The anti class-II MAb were; B721 (anti-DP, $H$ ), or anti-DR plus anti-DQ MAb (Becton Dickinson) $(D)$, and the anti-class I MAb W6/32 $(D, H)$ were all added at 1:200 final dilution. Percent inhibition was calculated: $100-\{$ [net cpm of experimental culture/net cpm of control culture] $\times 100\}$, where net cpm reflects the mean cpm of quadruplicate cultures - mean cpm of the responder only cultures. The mean cpm of the control cultures (no serum added) were 12,000-25,000 for both type of responses. Polyclonal activation with the T cell mitogen PHA gave net cpm of $50,000-100,000$. The PHA responses were not inhibited by either OKT4A MAb or any of the sera tested (not shown). 


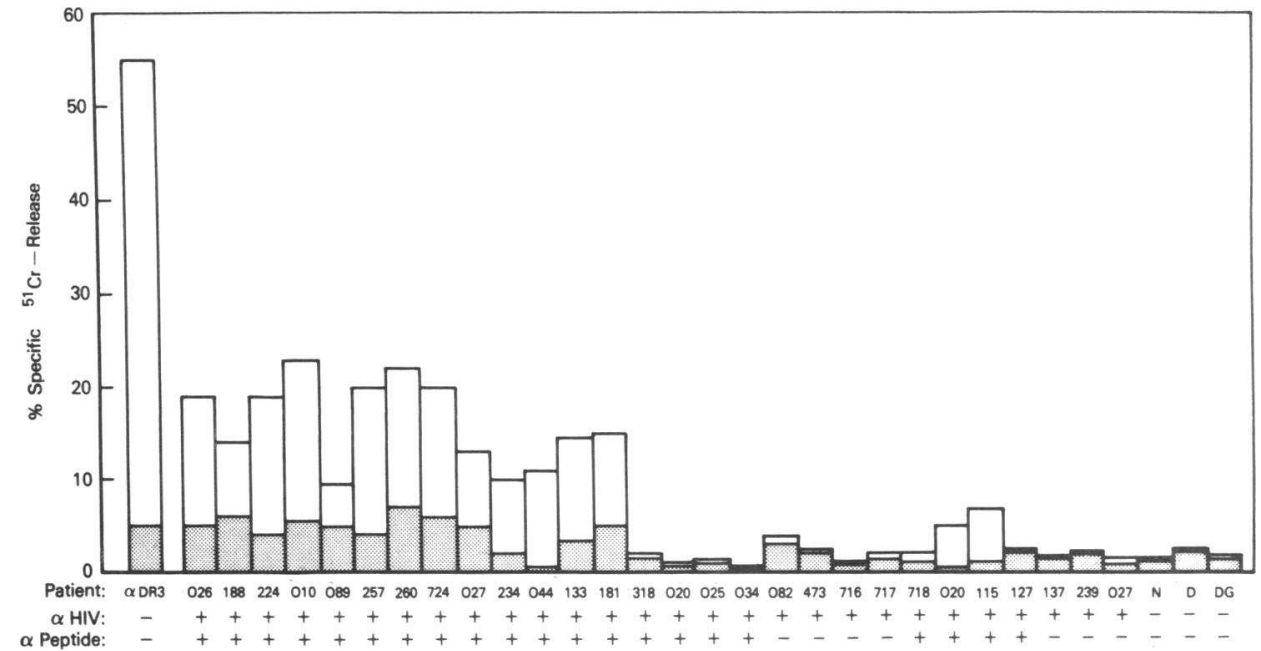

Figure 3. Antibody-dependent cellular cytotoxicity of class II bearing lymphoblastoid lines by sera from HIV I infected individuals. ADCC was measured using ${ }^{51} \mathrm{Cr}$-release assay as described in Methods. Briefly, either class II positive EBV transformed B cell lines (open bars) or class II negative cell lines (CEM, shaded bars) were labeled with ${ }^{51} \mathrm{Cr}$ for $1 \mathrm{~h}$. Labeled targets were incubated with test sera at 1:25 dilution (or control, haplotype specific typing serum, at 1:50 dilution) for 30 min at $37^{\circ} \mathrm{C}$ followed by addition of $2.5 \times 10^{5}$ PBL effector cells. ${ }^{51} \mathrm{Cr}$ release was measured after $16 \mathrm{~h}$ incubation. pressing cells by ADCC) could be removed by adsorption of these sera with the relevant class II-derived peptide linked to Sepharose beads.

In order to formally prove that the anti-class II peptide reactivity resides in the Ig fraction of the patients' sera, we passed several of the sera over a Sepharose-peptide column and eluted the bound material with low pH buffers (see Fig. 5, legend). As can be seen in Fig. 5 (top), the eluted materials from two sera produced sharp lines of precipitation with goatanti-human IgG. The eluted materials were also analyzed by

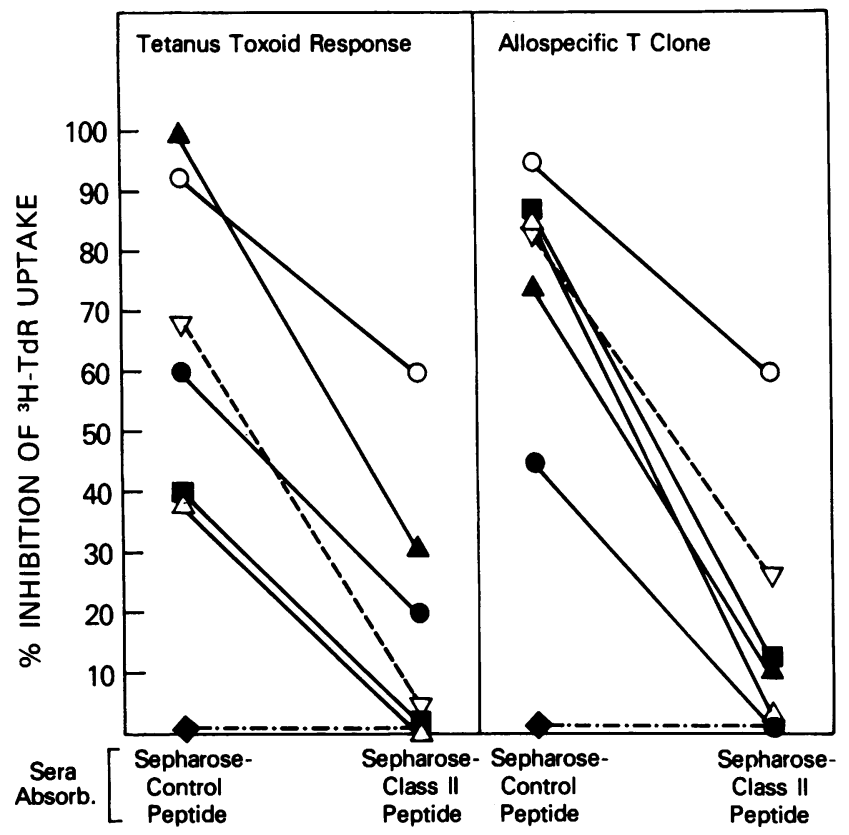

Figure 4. Adsorption of sera with Sepharose-linked class II derived peptide remove their inhibitory activity. Five inhibitory sera (and one control) were adsorbed overnight (1:1 vol/vol), with Sepharose beads covalently linked to the class II or GP41-derived homologous peptide, or to control peptides (from either class II aa 35-46, or CD4 aa 314-331). The adsorbed sera were separated from the beads by microfuge centrifugation and were added to in vitro cultures at 1:20 dilution. The percent inhibition of the tetanus toxoid and allospecific $T$ cell clone responses was calculated as described in the legend to Fig. 2. The different symbols represent different patients' sera. polyacrylamide gel electrophoresis. As can be seen in Fig. 5 (bottom), the major component of the eluted material migrated as IgG with a minor band migrating like albumin. Using the human IgG standard it was possible to estimate the concentration of the cross-reactive anti-class II antibodies in the original sera. These values were calculated to be 4 and $6 \mu \mathrm{g} / \mathrm{ml}$ in the sera of patient 718 and patient 257 , respectively. At the time of testing, both patients were at an early stage of HIV I-infection. Their CD4 ${ }^{+}$-cell numbers were 722 and $682 / \mathrm{mm}^{3}$, respectively. While still asymptomatic, they were found re-
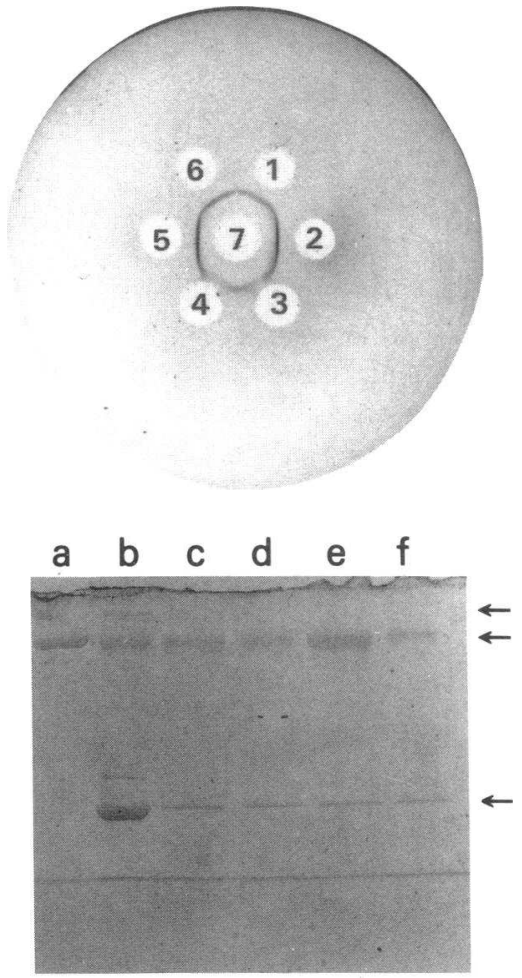
acrylamide gel at constant voltage $(200 \mathrm{~V})$ for $42 \mathrm{~min}$. The lanes represent: (a) human MAb (IgG $)$ (700 ng), (b) serum 718 (1:400), (c) 718 eluate (1:2). (d) 718 eluate (1:3), (e) 257 eluate (1:2), $(f) 257$ eluate (1:3). Arrows indicate the position of (from top to bottom); IgM, IgG, and albumin. 


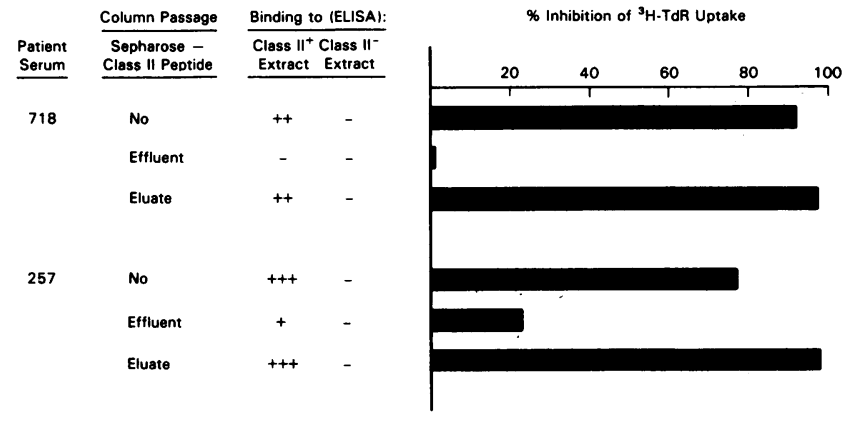

Figure 6. Affinity purified anti-class II-peptide antibodies bind to intact class II molecules and suppress in vitro $\mathrm{T}$ cell responses. Untreated sera (patients 718 and 257, see Fig. 5) as well as their Sepharose-class II peptide effluents and eluates were tested for their ability to bind to plates coated with cell extracts enriched for class II molecules (reference 4 ) or with similar extracts from a class II negative cell line. Binding index $(\mathrm{BI})=\mathrm{OD}$ of sample $(1: 100) / \mathrm{OD}$ of negative control $(1: 100)+2$ SD. ELISA results are ranked as follows: $(+)$ BI $=1.5-2 ;(++), \mathrm{BI}=2.1-3.5 ;(+++), \mathrm{BI}=>3.5$. The sera and their column effluents were tested for their ability to block the proliferative response of $\mathrm{CD}^{+} \mathrm{T}$ cell clone at 1:20 dilution, the eluates were added at 1:200 (718) and 1:300 (257). Percent inhibition was calculated as described in the legends to Figs. 2 and 4.

cently to have markedly reduced IL 2 production in response to in vitro stimulation with tetanus toxoid, influenza, and xenogeneic cells (CD4-dependent activation), but responded normally to mitogens and allogeneic stimulation (which can trigger CD8 as well as CD4-bearing cells).

The affinity purified antibodies from these patients were tested for their ability to bind to plates coated with; $(a)$ class II peptide (or control peptide), (b) cell extracts enriched for class II molecules (prepared as described in reference 4) and (c) similar extracts from class II negative cells. In addition, they were tested for their ability to suppress the in vitro proliferative response of a CD4 ${ }^{+} \mathrm{T}$ cell clone (Fig. 6). Both sera and their peptide-column eluates (but not column effluents) bound to plates coated with the homologous peptides from either gp41 or class II, but not to control peptides (data not shown). They also bound to plates coated with intact class II molecules from cell extracts (but not to similar extracts from class II-negative cells) (Fig. 6). Furthermore, these eluates could inhibit the T cell clone response at a 10-20-fold higher dilution compared to the original sera (Fig. 6).

We are currently purifying more of the cross-reactive antibodies from patients' sera in order to conduct additional biochemical analyses including binding to Western blots impregnated with HIV I proteins and human class II antigens of different haplotypes. In preliminary experiments it was found that, while the untreated sera react with multiple HIV I proteins on immunoblots, the eluates from the class II-peptide column react only with gp160 and gp41 on the same HIV I immunoblots.

\section{Discussion}

This study demonstrates that a significant number of HIV I-infected individuals generate antibodies against a conserved hydrophilic region in the $\mathrm{COOH}$-terminus of gp41 (aa 837-844) (indicating that this region contains an immunogenic site for B cells), and that these antibodies cross-react strongly on an homologous sequence localized in the $\mathrm{NH}_{2}$-terminus of all class II beta chains (aa 19-25). More importantly, these cross-reactive antibodies are capable of binding also to the native two-chain class II molecules which, in the human, are expressed on macrophages, $B$ cells, and activated $\mathrm{T}$ cells. Because of the proximity of the class II cross-reactive epitope to the antigen binding regions on the class II molecules, it was possible that their binding to antigen presenting cells in vivo may interfere with the normal cellular interactions required for the stimulation of $\mathrm{CD}^{+} \mathrm{T}$-helper cells. Murine MAb, and affinity purified antibodies from HIV I-infected individuals, both with specificity for the homologous gp41/class II sequence, were found to act as potent inhibitors of in vitro proliferative responses of normal $\mathrm{CD}^{+}$class II-restricted $\mathrm{T}$ cells. Experiments are underway to determine whether the blocking occurs at the level of the antigen presenting cells, the $\mathrm{T}$ cells, or both. In addition such antibodies were shown to eliminate class II-bearing cells by ADCC, and could conceivably contribute to the elimination of class II-bearing immune cells in vivo, including activated $\mathrm{CD}^{+} \mathrm{T}$ cells.

In an attempt to correlate the production of such crossreactive autoantibodies by HIV I-infected individuals with their disease progression we examined sera from both more advanced AIDS patients (Walter Reed stage 4-6) and from seropositive asymptomatic (Walter Reed stage 1-2), and a few ARC (stage 3) patients. Interestingly, irrespective of their disease stage, $\sim 35 \%$ of the sera tested contained the anti-class II cross-reactive antibodies. Thus, the production of such antibodies can occur early during the course of infection with the HIV I virus. While most of the patients at stages 1-2 are clinically disease free, it was recently found that many of them exhibit markedly reduced in vitro T cell responses (e.g., IL2 production, proliferation, CTL induction) against viruses and soluble antigens. In particular they demonstrate a defect in the $\mathrm{CD}^{+} \mathrm{T}$ cell-dependent activation pathways even at a stage when relatively high numbers of $\mathrm{CD}^{+} \mathrm{T}$ cells $(500-1,000 /$ $\left.\mathrm{mm}^{3}\right)$ are maintained $(8$, and Clerici et al. manuscript in preparation). It is conceivable that the cross-reactive autoantibodies that were described in this report may contribute to these early immune dysfunctions. Indeed, in a parallel study, many of the seropositive asymptomatic individuals that tested positive (by ELISA) against the class II-peptide, were found to have various degrees of $T$-helper cell abnormalities. We are currently following these patients prospectively, in order to correlate the presence of anti-class II autoantibodies with their disease progression.

In summary, the autoimmune mechanism described here, could account for the seemingly paradoxical observations in many HIV I-infected individuals of: $(a)$ deficient $T$ helper function in the presence of adequate numbers of $\mathrm{CD}^{+}$cells $(8$, 9 ), and (b) depletion of $\mathrm{CD}^{+} \mathrm{T}$ cells despite the very low frequency of HIV-I infected cells (10). Thus, in addition to its direct cytopathic effects on human T helper cells, HIV-I, similar to other infectious agents $(1,2,11)$, contains several epitopes which closely mimic self proteins $(4,12,13)$. Such molecular mimicry leads to break down of self-tolerance in infected individuals, and as demonstrated here to the generation of autoantibodies that can bind to cells in the immune system and impair their function.

These findings also imply that attempts to vaccinate individuals with the gp 160 or gp41 subunits, could induce autoantibodies reacting with HLA class II-bearing cells. Thus, it may 
be important to eliminate the gp41 epitope which is homologous to the class II molecules from the cloned envelope gene or replace it with an antigenically inert sequence.

\section{Acknowledgments}

We wish to thank Dr. Frank Robey for the preparation of all the peptides used in this study, and Drs. Thomas Hoffman, Theresa Gerrard, and David Katzenstein for critical review of the manuscript.

This study was partially supported by a NIH Intramural AIDS Research Fund.

\section{References}

1. Oldstone, M. B. A. 1987. Molecular mimicry and autoimmune disease. Cell. 50:819-820.

2. Fujinami, R. S., and M. B. A. Oldstone. 1985. Amino acid homology between the encephalitogenic site of myelin basic protein and virus: mechanism for autoimmunity. Science (Wash. DC). 230:1043-1045.

3. Ziegler, J. L., and D. P. Stites. 1986. Hypothesis: AIDS is an autoimmune disease directed at the immune system and triggered by a lymphotropic retrovirus. Clin. Immunol. Immunopathol. 41:305-313.

4. Golding, H., F. A. Robey, F. T. Gates III, W. Linder, P. R. Beining, T. Hoffman, and B. Golding. 1988. Identification of homologous regions in human immunodeficiency virus I gp4I and human class II beta 1 domain. J. Exp. Med. 167:914-923.

5. Quinnan, G. V., N. K. Kirmani, A. H. Rook, J. F. Manischewitz, L. Jackson, G. Moreschi, G. W. Santos, R. Saral, and W. H. Burns. 1982. Cytotoxic $T$ cells in cytomegalovirus infection. HLA restricted T-lymphocyte and non-T-lymphocyte cytotoxic responses correlate with recovery from cytomegalovirus infection in bone marrow transplant patients. $N$. Engl. J. Med. 307:7-13.
6. Golding, H., J. McClusky, T. I. Munitz, R. N. Germain, D. H. Margulis, and A. Singer. 1985. T cell recognition of a chimeric class II/class I MHC molecule and the role of L3T4. Nature (Lond.). 317:425-427.

7. Stricker, R. B., T. M. McHugh, D. J. Moody, W. J. W. Morrow, D. P. Stites, M. A. Shuman, and J. A. Levy. 1987. An AIDS-related cytotoxic autoantibody react with a specific antigen on stimulated $\mathrm{CD}^{+} \mathrm{T}$ cells. Nature (Lond.). 327:710-713.

8. Shearer, G. M. 1986. A model for the selective loss of MHC self-restricted $\mathrm{T}$ cell immune responses during the development of AIDS. J. Immunol. 137:2514-2521.

9. Lane, H. C., J. M. Depper, W. C. Green, G. Whalen, T. A Waldmann, and A. C. Fauci. 1985. Qualitative analysis of immune function in patients with the acquired immunodeficiency syndrome. Evidence for a selective defect in soluble antigen recognition. $N$. Engl. J. Med. 313:79-81.

10. Harper, M. E., L. M. Marselle, R. C. Gallo, and F. Wong-Staal. 1986. Detection of lymphocytes expressing human T-lymphotropic virus type III in lymph nodes and peripheral blood from infected individuals by in situ hybridization. Proc. Natl. Acad. Sci. USA. 83:772-776.

11. Clarke, M. F., E. P. Gelmann, and M. S. Reitz, Jr. 1983. Homology of human T-cell leukemia virus envelope gene with class I HLA gene. Nature (Lond.). 305:60-62.

12. Reither, W. E., J. E. Blalock, and T. K. Brunck. 1986. Sequence homology between acquired immunodeficiency syndrome virus envelope protein and interleukin 2. Proc. Natl. Acad. Sci. USA. 83:91889192.

13. Weigent, D. A., P. D. Hoeprich, K. L. Bost, T. K. Brunck, W. E. Reither, and J. E. Blalock. 1986. The HTLV-III envelope protein contains a hexapeptide homologous to a region of interleukin-2 that binds to the interleukin-2 receptor. Biochem. Biophys. Res. Commun. 139:367-374. 